УДК 37

DOI $10.21661 / \mathrm{r}-552102$

\title{
М.А. Синовац
}

\section{СОВРЕМЕННЫЕ ПОДХОДЫ И МЕТОДЫ В ОБУЧЕНИИ АНГЛИЙСКОМУ ЯЗЫКУ}

Аннотация: обучение иностранному языку включает в себя два основных компонента: транслирование и получение информации. На практике учитель старается изо всех сил передать знание, которым он владеет. Использование инновационных методов в образовательных учреждениях расширяет права и возможности как учеников, так и учителей. Инновационные технологии способствуют развитию человеческого потенщиала страны. При наличии ряда образовательных возможностей, доступных учащимся современного поколения, возникли новые тенденции, которые полностью изменили облик традиционной системы образования. Последние тенденции в методологии отражают жизненно важную роль сектора образования в целом с его интернализацией образовательного процесса, акиентом на качество, расширением применения новых технологий. Теория и методы постоянно развиваются и в области ELT. B статье представлены известные тенденции в ELT, которые были использованы практически в последнее время во всем мире. Новые тенденции в обучении иностранному языку становятся известными как GTM, коммуникативный метод.

Ключевые слова: инновационные методы, инновационные технологии, учебный процесс, кооперативное обучение, ИКТ, ELT.

\section{M.A. Sinovats}

\section{MODERN APPROACHES AND METHODS IN TEACHING ENGLISH}

Abstract: teaching a foreign language includes two main components: to impart and to receive information. In practice, the teacher tries his best to convey the knowledge that he has. The use of innovative methods in educational institutions ex- 
pands the rights and opportunities of both students and teachers. Innovative technologies contribute to the development of the country's human potential. With a number of educational opportunities available to students of the modern generation, new trends that have completely changed the face of the traditional education system have emerged. Recent trends in the methodology reflect the vitally important role of the education sector as a whole, with its internalization of the educational process, emphasis on quality, and increased use of new technologies. Theory and methods are constantly being developed in the field of ELT. The article presents well-known trends in ELT that have been practically used all over the world recently. New trends in foreign language teaching are becoming known as GTM, a communicative method.

Keywords: innovative methods, innovative technologies, educational process, cooperative learning, ICT, ELT.

\section{Введение}

Новые технологий, о которых говорится в статье, относятся как к методике, так и к материалам, используемым в преподавании языка. В статье рассматриваются тенденции образования, новые и уже существующие методы, новый дизайн преподавания, современные устройства, необходимые для изменений, роль ИКТ в преподавании английского языка. Преподавание английского языка претерпело огромные изменения за эти годы, особенно за последние десять лет. Ранее ученики и студенты были обременены изучением и усвоением материала в рамках лекций с подборкой соответствующей информации из предписанных текстов. В настоящее же время такие альтернативные подходы, как освоение коммуникативных, технических навыков, навыков межличностного общения, ИКТ-грамотность, приобретают все большее значение. Потребность в успешных выпускниках, способных конкурировать в жесткой среде выживания мирового рынка, сегодня очень востребована. Времена, мода, отношения людей меняются, но обескураживает тот факт, что за последнее столетие учебная программа английского языка практически не претерпела никаких изменений. Многое изменилось в отношении людей к тому, что они воспринимают как язык. Все же жесткие учебные 
программы и огромные учебные планы продолжают угрожать ученикам и студентам. Учителя, которые практиковали метод грамматического перевода в течение предыдущего десятилетия, полагались исключительно на черную доску как подходящий инструмент для передачи коммуникативных навыков и нюансов английского языка, все еще преподают. Над проекторами, выступающими еще одним медиумом для учителя, все еще доминирует классная комната. Такие учителя верили в изречения учения и практики. Ранее исследователи уделяли большое внимания аутентичному и содержательному контекстуализированному дискурсу. Затем они сосредоточились на успешном изучении второго языка взрослыми как параллельном процессе обучения иностранному языку. Другими словами, преподаватели излагали содержание лекции, а студенты слушали ее. Режим обучения имел тенденцию быть пассивным, и учащиеся играли незначительную роль в процессе обучения. Со временем многие преподаватели и студенты обнаружили, что традиционный лекционный подход в классе имеет ограниченную эффективность как в преподавании, так и в обучении. Этот метод оставался на практике в течение длительного периода времени из-за его ориентации на функциональное использование английского языка. Но, тем не менее, этот метод был неэффективным. Потребовалось много времени, хороший бюджет и небольшой размер класса для того, чтобы ситуация начала меняться. Но даже этого было недостаточно. Проблемы привели к другому методу, который называется аудио-лингвистическим. Затем появился прямой метод обучения иностранному языку с использованием аудиовизуальных средств.

\section{Современные тенденциии преподавания английского языка}

Метод коммуникативного обучения более ориентирован на ученика и отнимает меньше времени. Качество преподавания лучше, и прикладное общение студентов на английском языке может быть эффективно культивировано, а это означает, что коммуникативная компетентность студентов будет успешно развиваться. Язык в образовании в идеале обычно и строится на такой естественно приобретенной языковой способности, которая обогащаясь грамотностью превращается 
в инструмент для абстрактного мышления и приобретения академических знаний. Учителя используют различные тексты на английском языке для перевода, аудирование и грамматические тесты. С распространением планшетов и смартфонов считается, что учебник исчезнет через несколько лет.

Осознавая необходимость преобразований: преподаватели английского языка созывают различные типы конференций и семинаров, чтобы создать платформу и познакомиться с предстоящими идеологиями в ELT, а также повысить свой профессиональный уровень. Академическая квалификация сама по себе не может помочь учителям расти профессионально, с другой стороны, они должны быть оснащены современными материалами. Существовало слишком много методик преподавания английского языка. Мировая глобализация неотделима от преподавания английского языка - это развитие информационно-коммуникационных технологий. Новые тенденции в преподавании английского языка, такие как интерактивный подход, развиваются в результате постоянных исследований.

\section{Веб-обучение}

Веб-обучение - одна из самых быстро развивающихся областей. Существуют тысячи веб-классов английского языка, которые предлагают обучение различным базовым языковым навыкам, таким как обучение, говорение, чтение и письмо, интерактивными способами. Некоторые распространенные технологии заключаются в следующем: студенты могут переписываться с носителями языка с помощью электронной почты, создав личную учетную запись электронной почты (g-mail, yahoo, hotmail и т.д.), которая является бесплатной. Студенты могут отправить свою домашнюю работу по почте учителям и получить ее проверенной. Учитель может создать свой блог. Блог - это личный или профессиональный журнал, часто обновляемый для общественного потребления. Блоги позволяют загружать и связывать файлы, которые очень подходят для использования в качестве онлайновых личных журналов для студентов. Блог становится коммуникативным и интерактивным, когда участники берут на себя несколько ролей, как читатели / рецензенты, которые отвечают на сообщения других авто- 
ров, и как писатели-читатели, которые, возвращаясь к своим собственным сообщениям, реагируют на критику своих собственных сообщений. Читатели, в свою очередь, могут комментировать то, что они читают, хотя блоги также могут быть размещены в защищенных средах. Ноутбуки с камерами имеют аудиофункции и технологические инструменты. Студенты могут общаться со своими учителями и друзьями, которые находятся далеко.

\section{Дивайсы нового поколения}

В этом году выставка потребительской электроники (CES), проходившая в Лас-Вегасе, дала представление о новаторских устройствах, предназначенных исключительно для студентов. Эти экспонаты варьировались от 3D-принтеров до умных часов. Требованиям молодежи соответствуют новые устройства, позволяющие учиться, общаться в социальных сетях, путешествовать и быть мобильным. Устройства потоковой передачи мультимедиа, такие как Google chrome cast и Rokku, делают групповые исследования интерактивными, а презентации удивительными. Одно из устройств может транслировать медиа на смарт-телевизор с помощью ключа. Другое устройство - электронная книга - это благо для нового поколения, живущего в движении. Совершенно новая бумага kindle white - это еще одно изобретение. Портативный блок развертки документа - отличное приложение, которое сортирует Flatbet фото и ноутбука. Другие устройства - это диктофоны, такие как Olympus, могут быть использованы для записи всех лекций по английскому языку и воспроизведения в удобное время. Разработаны новые языковые программы, учебные программы для эффективного развития навыков учащихся. Четкое описание содержания в терминах лингвистической компетенции, социолингвистической компетенции и прагматической компетенции составляет язык. С помощью дескрипторных шкал измеряется уровень владения языком учащегося. Дескрипторы состоят из ряда утверждений can do, которые получили большое внимание. В процессе преподавания и обучения особое внимание уделяется также вовлеченности учащихся и расширению прав и возможностей учителя. 


\section{Роль современного учителя}

Исследователи определили термин «роль» как технический термин, который первоначально пришел из социологии и относится к общему понятию того, как должен вести себя индивид. Несколько методик выделяют различные роли для преподавателя языка. В одних роль учителя - это часть дизайна, компонент метода. В других - посредник в обучении, надзиратель, классный руководитель, консультант, а иногда и со-коммуникатор с учащимися. Для третьих учитель играет роль контролера, организатора, оценщика, промоутера, участника, ресурса, наставника и наблюдателя. Задача современного преподавания - это коммуникативное обучения языку. Экспериментальное обучение или обучение на практике как основная концептуальная основа TBLT.

Task-based language teaching (TBLT), также известный как task-based instruction (TBI), фокусируется на использовании аутентичного языка и на том, чтобы просить студентов выполнять значимые задачи, используя целевой язык. Такие задачи могут включать посещение врача, проведение собеседования или обращение в службу поддержки клиентов за помощью TBLT ломает барьеры традиционного класса, потому что в TBLT. Роль ученика существенно меняется. Учитель становится истинным посредником, учителем для исключительно диалогического общения. Роль учителя не избегается полностью, но ограничена: учитель должен быть проводником на стороне. Роль учителя - это ведущий, независимый участник, аналитик, советник и менеджер по обработке групповых данных.

\section{Заключение}

Во всем мире информационные технологии кардинально меняют способы обучения и деятельность студентов, преподавателей и сотрудников. Поскольку спрос на технологии продолжает расти, колледжи и университеты предоставляют различные виды услуг для студентов, от прачечной до доставки еды онлайн. Технологии также меняют и методы работы в классе. Планшетные ПК, компактные компьютеры, позволяющие писать заметки прямо на экран специальной ручкой, 
заменяют архаичный проектор. С помощью планшетной технологии преподаватель может делать заметки на диаграммах и электронных таблицах и отправлять их непосредственно на компьютеры своих студентов. Традиционный метод делал большой акцент на самом учителе и был ориентирован на учителя. Повторяющаяся практика, механические упражнения и запоминание являлись отличительными чертами традиционных методов. Качество обучения зависело от того, насколько хорошо учитель преподает. Современные же тенденции и методы оценки ELT ставят целью передачу информации или знаний в сознание учащихся.

\section{Сиисок литературы}

1. Almekhlafi A. Влияние компьютерного обучения языку (CALL) на успеваемость и отношение учащихся школ EFL Объединенных Арабских Эмиратов // Journal of Interactive Learning Research. - 2006. - №17 (2). - C. 121-142.

2. Современные тенденции в преподавании английского языка по Ен Ким // Журнал обучения английскому языку. Трехгодичное издание по изучению преподавания английского языка. -2011. - Т. 1.

3. Уорик Э. 2001. Вывод: чему мы научились? // International Journal of Educational Research. - 2001. - №35.

4. Бавискар С. Содержание и методика преподавания английского языка (коммуникативное обучение языку) / С. Бавискар, Махаджан. - Jalgaon: Prashant Publications, 2012.

5. Зер М.-Э. Тенденции в образовании изучающих английский язык / М.Э. Зеp. -2008 .

6. Culture in Second Language Teaching and Learning; Cambridge University Press - M., 2011. - 262 c.

7. Лингводидактические проблемы обучения иностранным языкам. Вып. 2. - М.: Изд-во Санкт-Петербургского университета, 2011. - 176 с.

8. Методика обучения иностранным языкам в средней школе. - КАРО, 2013. -224 c.

9. Развитие речевой активности на уроках иностранного языка. - М.: Просвещение, 2012. - 244 с. 
10. Аркусова И.В. Современные педагогические технологии при обучении иностранному языку (структурно-логические таблицы и практика применения). - М.: НОУ ВПО МПСИ, 2012. - 128 с.

11. Бим И.Л. Профильное обучение иностранным языкам на старшей ступени общеобразовательной школы. Проблемы и перспективы / И.Л. Бим. - М.: Просвещение, 2011. - 168 с.

\section{References}

1. Almekhlafi, A. (2006). Vliianie komp'iuternogo obucheniia iazyku (CALL) na uspevaemost' i otnoshenie uchashchikhsia shkol EFL Obedinennykh Arabskikh Emiratov. Journal of Interactive Learning Research, 17 (2), 121-142.

2. Sovremennye tendentsii v prepodavanii angliiskogo iazyka po En Kim. Zhurnal obucheniia angliiskomu iazyku. Trekhgodichnoe izdanie po izucheniiu prepodavaniia angliiskogo iazyka. -2011, T. 1.

3. Uorik, E. (2001). Uorik E.. Vyvod: chemu my nauchilis'?. International Journal of Educational Research, 35.

4. Baviskar, S. (2012). Soderzhanie i metodika prepodavaniia angliiskogo iazyka (kommunikativnoe obuchenie iazyku). Jalgaon: Prashant Publications.

5. Zer M.-E. Tendentsii v obrazovanii izuchaiushchikh angliiskii iazyk.

6. (2011). Culture in Second Language Teaching and Learning; Cambridge University Press. M.

7. (2011). Lingvodidakticheskie problemy obucheniia inostrannym iazykam. Vyp. 2. M.: Izd-vo Sankt-Peterburgskogo universiteta.

8. (2013). Metodika obucheniia inostrannym iazykam v srednei shkole. KARO.

9. (2012). Razvitie rechevoi aktivnosti na urokakh inostrannogo iazyka. M.: Prosveshchenie.

10. Arkusova, I. V. (2012). Sovremennye pedagogicheskie tekhnologii pri obuchenii inostrannomu iazyku (strukturno-logicheskie tablitsy i praktika primeneniia). M.: NOU VPO MPSI.

11. Bim, I. L. (2011). Profil'noe obuchenie inostrannym iazykam na starshei stupeni obshcheobrazovatel'noi shkoly. Problemy i perspektivy. M.: Prosveshchenie. 
Синовац Марина Анатольевна - учитель, МБОУ «Школа №56», Россия, Тольятти.

Sinovats Marina Anatolyevna - teacher, MBGEI “School №56”, Russia, Tolyatti. 